\title{
Prediction of thermal induced color changes of chicken breast meat during convective roasting: A combined mechanistic and kinetic modelling approach
}

Rabeler, Felix; Skytte, Jacob Lercke; Feyissa, Aberham Hailu

Published in:

Food Control

Link to article, DOI:

10.1016/j.foodcont.2019.04.018

Publication date:

2019

Document Version

Peer reviewed version

Link back to DTU Orbit

Citation (APA):

Rabeler, F., Skytte, J. L., \& Feyissa, A. H. (2019). Prediction of thermal induced color changes of chicken breast meat during convective roasting: A combined mechanistic and kinetic modelling approach. Food Control, 104, 42-49. https://doi.org/10.1016/j.foodcont.2019.04.018

\section{General rights}

Copyright and moral rights for the publications made accessible in the public portal are retained by the authors and/or other copyright owners and it is a condition of accessing publications that users recognise and abide by the legal requirements associated with these rights.

- Users may download and print one copy of any publication from the public portal for the purpose of private study or research.

- You may not further distribute the material or use it for any profit-making activity or commercial gain

- You may freely distribute the URL identifying the publication in the public portal 


\section{Accepted Manuscript}

Prediction of thermal induced color changes of chicken breast meat during convective roasting: A combined mechanistic and kinetic modelling approach

Felix Rabeler, Jacob Lercke Skytte, Aberham Hailu Feyissa

PII:

S0956-7135(19)30173-2

DOI:

10.1016/j.foodcont.2019.04.018

Reference:

JFCO 6606

To appear in:

Food Control

Received Date:

11 February 2019

Accepted Date:

19 April 2019

Please cite this article as: Felix Rabeler, Jacob Lercke Skytte, Aberham Hailu Feyissa, Prediction of thermal induced color changes of chicken breast meat during convective roasting: A combined mechanistic and kinetic modelling approach, Food Control (2019), doi: 10.1016/j.foodcont. 2019.04.018

This is a PDF file of an unedited manuscript that has been accepted for publication. As a service to our customers we are providing this early version of the manuscript. The manuscript will undergo copyediting, typesetting, and review of the resulting proof before it is published in its final form. Please note that during the production process errors may be discovered which could affect the content, and all legal disclaimers that apply to the journal pertain. 
1 Prediction of thermal induced color changes of chicken breast meat during convective roasting:

2 A combined mechanistic and kinetic modelling approach

3

4

5

6 Felix Rabeler*, Jacob Lercke Skytte, Aberham Hailu Feyissa

7 Food Production Engineering, National Food Institute, Technical University of Denmark (DTU),

8 Denmark

9

10

$11{ }^{*}$ Corresponding author:

12 Søltofts Plads, 2800, Kgs. Lyngby, Denmark

13 Email address: felra@,food.dtu.dk, Tel.: +45 45252531

14 ORCID: 0000-0001-8800-0280

15

16

17 Keywords: Heat and mass transfer, Maillard reaction, mechanistic modelling, poultry meat, surface

18 browning, thermal processing, quality control

19

20 


\section{Abstract}

22 Consumers first assess the quality of roasted chicken meat by its appearance. However, studies that 23 evaluate the color changes during thermal processing are lacking. The aim of this work was, therefore, 24 to develop a mathematical model that can predict the lightness $\left(L^{*}\right)$ changes of chicken breast meat 25 during convective roasting.

26 Chicken breast meat was roasted in a convection oven and the internal as well as surface lightness was 27 measured at different time steps. The lightness of chicken meat increases in the beginning of the 28 process, which shows a whitening due to myoglobin denaturation. When the surface temperature is 29 rising above $88^{\circ} \mathrm{C}$, the lightness starts to decrease again as a result of browning reactions.

30 We developed a non-isothermal kinetic model that describes the browning (decrease of the lightness) of 31 the surface as function of temperature, water activity and roasting time. The kinetic models for the 32 whitening and browning were then coupled to the validated mechanistic model for chicken meat roasting. This enables the prediction of the internal as well as surface lightness development from the spatial temperature and water activity changes. The validation of the model showed a good agreement between model predictions and experimental values for different roasting conditions.

Overall, the developed model allows the prediction of the spatial lightness distributions with roasting

37 time and advances our understanding of the mechanisms of heat induced color changes. Thus, the model can be applied to control and optimize the roasting of chicken meat to ensure the quality and safety for the consumer. 


\section{Introduction}

41 The color and appearance of cooked chicken meat are the first quality parameters that are evaluated by

42 the consumers, even before the actual consumption (Guerrero-Legarreta and Hui, 2010). Especially the

43 color of the cooked meat provides information about the quality, flavor and safety of the

product(Grunert et al., 2004; Pedreschi et al., 2006). Therefore, the color of cooked chicken breast meat

is an important quality parameter in professional kitchens or the food industry that needs to be controlled thoroughly.

In the beginning of the cooking process, the color of chicken breast meat is changing from pink-red to

an off-white color. This change is mainly caused by the heat induced denaturation of myoglobin to ferro- and ferrihemochromes, resulting in the color fading (King and Whyte, 2006). The denaturation of myoglobin takes place in the temperature range from 55 to $80^{\circ} \mathrm{C}$, while the rate and amount of denaturation is correlated mainly to the temperature and time of heating (Lawrie and Ledward, 2006; Martens et al., 1982; Rabeler and Feyissa, 2018a). Moreover, the denaturation of structural proteins, like myofibrillar proteins could result in an increased light scattering from the surface and an optical masking of the hemeproteins. The protein denaturation leads to a reduction of the fiber diameter and larger gabs between the individual fibers. This allows for an increased light scattering and, consequently, the surface and inner regions of the meat product seems lighter (Hughes et al., 2014; Martens et al., 1982). However, especially at or close to the sample surface where the temperature is rising fast, the is mainly caused by myoglobin denaturation (Kondjoyan et al., 2014) . When the temperature is further increasing, the surface dries out due to water evaporation which leads to more greyish and darker colors. When the temperature is rising above 85 to $90{ }^{\circ} \mathrm{C}$, caramelization as well as Maillard reactions take place (Kondjoyan et al., 2014; Nakamura et al., 2011). The latter, also 
62 known as non-enzymatic browning is the reaction between reducing sugars and the amino groups of 63 proteins, peptides and free amino acids. This results in the formation of the typical flavor and taste of 64 roasted meat as well as the formation of the typical brown color (Shahidi et al., 2014). The formation of 65 colored compounds (low molecular weight) as well as melanoidins (high molecular weight) during the Maillard reaction is mainly responsible for the browning. Furthermore, reactions in the early stages of the Maillard reaction could lead to the development of brown colors (Ames et al., 1993; Ledl and Schleicher, 1990; Namiki and Hayashi, 1981). When the surface temperature exceeds $150^{\circ} \mathrm{C}$ carbonization reactions are taking place, which results in the formation of dark colors and a burned appearance (Matsuda et al., 2013).

The final color of roasted chicken breast meat is still relying on the cook and a look approach, thus, it depends highly on the skills of the operator or chef. If it is possible to predict the color change during the heating, a better control of the process could be achieved. Kinetic models that describe the change of the color with roasting time can help to understand, predict and control the process to obtain a final high quality product (Haefner, 2005; Van Boekel, 2008).

Kinetic models were developed for the color change of beef (redness, $a^{*}$ ) and chicken breast meat (lightness, $L^{*}$ ) during isothermal heating in water baths (Goñi and Salvadori, 2011 and Rabeler and Feyissa, 2018a, respectively). However, in moist surroundings no browning reactions take place in the studied temperature range $\left(40\right.$ to $\left.100^{\circ} \mathrm{C}\right)$. Thus, the kinetic models are not able to describe the browning at the surface of the meat product during a roasting process. Matsuda et al. (2013) investigated the change of the surface color of fish during grilling and developed kinetics model to describe the development as function of the measured surface temperature. However, the browning of the surface is not only a function of the temperature development but the change of the moisture content or water activity with time (Shahidi et al., 2014). 
85 The accurate measurement of the surface temperature or moisture content is difficult or even not

86 possible (Purlis and Salvadori, 2009; Zanoni et al., 1995). Mechanistic models, which are based on

87 principle physical laws, are able to predict the complex change in temperature and moisture content of

88 the product during heating. By combining kinetic models with models of heat and mass transfer (a

combined modeling approach) the local quality change (for example texture) can be obtained

90 (Kondjoyan et al., 2014; Rabeler and Feyissa, 2018b). For the baking of bread different researchers

have shown that it is possible to predict the change of the surface color by combining kinetic models

with mathematical models of heat and mass transfer (Purlis and Salvadori, 2009; Zanoni et al., 1995;

93 Zhang and Datta, 2006).

94 However, for chicken breast meat no studies are available that describe the color changes during

95 convective roasting. Therefore, the aim of this work is to develop a combined model which allows the prediction of the spatial lightness $\left(L^{*}\right)$ changes as function of the local temperature and water activity development. Our hypothesis is that by combining kinetic models that describe the lightness changes, with the validated mechanistic model of chicken meat roasting it is possible to predict the lightness change as function of roasting time and process settings. Validation trials with an independent data set will then show the accuracy and reliability of the developed combined model.

\section{2. Mathematical models}

\section{2.1. Kinetic model to describe the whitening of the chicken meat}

103 The whitening of chicken breast meat during heating was described by Rabeler and Feyissa (2018a)

104 with a modified rate law as function of sample temperature and heating time (Eq. (1)):

$105 \frac{\partial L_{w h}{ }^{*}}{\partial t}=k_{w h}(T)\left(L^{*}{ }_{\infty}-L_{w h}{ }^{*}\right)^{n}$ 
106 with the lightness $L^{*}$ at time $t$, the non-zero equilibrium value $L^{*}{ }_{\infty}$, the reaction order $n$ and the reaction

107 rate constant $k\left(\mathrm{~min}^{-1}[\mathrm{Q}]^{1-\mathrm{n}}\right)$. The common Arrhenius equation was used to describe the temperature

108 dependency of the reaction rate constant (for details see Rabeler and Feyissa (2018a)). The estimated

109 values for the activation energy $\left(E_{a}=101 \mathrm{~kJ} / \mathrm{mol}\right)$, pre-exponential factor $\left(k_{0}=2.65 \times 10^{15} \mathrm{~min}^{-1}\right)$,

110 reaction order $(n=1.1)$ and non-zero equilibrium $L^{*}$ value $\left(L_{\infty}{ }^{*}=87\right)$ by Rabeler and Feyissa $(2018 \mathrm{a})$

111 were used in this study.

\section{2.2. Kinetic model for the browning of chicken meat}

113 The browning of the chicken meat depends on the surface temperatures and starts at temperatures

114 greater than $85^{\circ} \mathrm{C}$ (Kondjoyan et al., 2014). During the roasting process the surface temperatures are

115 not constant but it is increasing nearly continuously with final temperatures of up to $150{ }^{\circ} \mathrm{C}$.

116 Consequently, the browning of the chicken meat surface is relying on the thermal history during

117 heating.

118 To address this non-isothermal process and taking the temperature-time history into account, a non-

119 isothermal kinetic was used to model the browning development at the top and bottom surface of the

120 chicken breast meat during the roasting process. The browning reaction was assumed to follow a first

121 order kinetic in the form of Eq. (2):

$122 \frac{\partial L^{*} b}{\partial t}=-k_{b}\left(T, a_{w}\right) L^{*}{ }_{b}$

123 The browning of the chicken meat surface relies not only on the temperature development but also the

124 change in the water content or water activity at the surface (Eichner and Karel, 1972). Therefore, Purlis

125 and Salvadori (2009) described for bread baking the reaction rate constant $k_{b}$ as function of the

126 temperatue and water activity. This appraoch was adapted in this study (Eq. (3)): 
$k_{b}=\left(p_{0}+\frac{p_{1}}{a_{w}(t)}\right) \exp \left(-\left(\frac{p_{2}+\frac{p_{3}}{a_{w}(t)}}{T(t)}\right)\right)$

128 with the water activity $a_{w}$, the temperature $T(\mathrm{~K})$ and the kinetic parameters $p_{0}, p_{1}, p_{2}$ and $p_{3}$.

129 If the temperature-time history is neglected during the estimation of the kinetic parameters it is likely

130 that the browning reaction, which is highly temperature dependent, has a larger error (Dolan, 2003).

131 However, the accurate measurement of the surface temperature or water activity during the roasting

132 process is difficult or even not possible (Purlis and Salvadori, 2009). Therefore, we used in this study

133 the validated mechanistic model of chicken breast meat roasting to obtain the change of the surface

134 temperatures and water activities as function of the roasting time (see section 2.3).

135 The kinetic models for the whitening (see section 2.1) and for the browning of the chicken meat surface

136 were combined with a Heaviside function $f$ which is centered at the start of the browning temperature,

$137 T_{b}$ (see Eq. (4b)). The function is going from 1 to 0 and it is defined as the transition between the two

138 kinetic models. This enables the estimation of the transition temperature for the surface browning and,

139 additionally, both phenomena can be described with one equation (Eq. (4a)):

$140 \quad \frac{\partial L^{*}}{\partial t}=f \frac{\partial L_{w h}{ }^{*}}{\partial t}+(1-f) \frac{\partial L_{b}{ }^{*}}{\partial t}=f k_{w h}(T)\left(L_{\infty}^{*}-L_{w h}{ }^{*}\right)^{n}+(1-f) k_{b}\left(T, a_{w}\right) L^{*}{ }_{b}$

141 Where $f$ is described as: $f=1-\frac{1}{1+\exp \left(T-T_{b}\right)}$

\section{$142 \quad$ 2.3. Mechanistic model of chicken breast meat roasting}

143 The validated mechanistic model of chicken breast meat roasting was used to obtain the development

144 of the surface temperatures and water activities with roasting time. For a detailed description of the

145 mechanistic model we refer the reader to Rabeler and Feyissa (2018b). The governing equation that is 
146 describing the heat transfer by convection and conduction is given by Eq. (5). The liquid water

147 transport inside the chicken breast meat by diffusion and convection is described with Eq. (6):

$148 \quad$ Heat transfer: $\quad c_{p, c m} \rho_{c m} \frac{\partial T}{\partial t}=\nabla\left(k_{c m} \nabla T\right)-\rho_{w} c_{p, w} u_{w} \nabla T$

$149 \quad$ Mass transfer: $\quad \frac{\partial C}{\partial t}=\nabla\left(-D \nabla C+C u_{w}\right)$

150 with $c_{p, i}, \rho_{i}$ and $k_{i}$ are the specific heat capacity, density and thermal conductivity, respectively, $T$ is the

151 temperature (K), $C$ is the moisture content ( $\mathrm{kg}$ of water $/ \mathrm{kg}$ of sample), $D$ is the moisture diffusion

152 coefficient $\left(\mathrm{m}^{2} / \mathrm{s}\right), u_{w}$ is the fluid velocity $(\mathrm{m} / \mathrm{s})$ and $t$ the time (s).

153 The thermal denaturation of proteins results in the shrinkage of the protein network as well as the

154 reduction of the water holding capacity. Thus, a pressure gradient is induced inside the chicken breast

155 meat. Darcy's law gives the relationship between this pressure gradient and the fluid velocity inside the

156 chicken breast meat during the roasting process (Eq. (7)) (Rabeler and Feyissa, 2018b):

$157 \quad u_{w}=\frac{-\kappa}{\mu_{w}} \nabla p$

158 with the swelling pressure $p=G^{\prime}\left(C-C_{e q}\right)$, the storage modulus $G^{\prime}(\mathrm{Pa})$, the water holding capacity

$159 C_{e q}$, the permeability $\kappa\left(\mathrm{m}^{2}\right)$, and the dynamic viscosity of the fluid $\mu_{w}(\mathrm{~Pa} \mathrm{~s})$.

160 The heat and mass transfer at the boundaries of the chicken breast meat sample was described with Eq.

161 (8) and Eq. (9), respectively (Rabeler and Feyissa, 2018b):

$162-k_{c m} \nabla T=h\left(T_{\text {oven }}-T_{\text {surf }}\right)$

$163-D \nabla C+C u_{w}=\beta_{\text {tot }}\left(C_{\text {surf }}-C_{\text {oven }}\right)$

164 where $h$ is the heat transfer coefficient $\left(\mathrm{W} /\left(\mathrm{m}^{2} \mathrm{~K}\right)\right)\left(h_{t o p}\right.$ at the top surface and $h_{b o t}$ at the bottom surface, 165 see Table 1), $T_{\text {oven }}$ and $T_{\text {surf }}$ are the oven and surface temperature (K), respectively, $\beta_{\text {tot }}$ is the total mass 166 transfer coefficient $(\mathrm{m} / \mathrm{s}), C_{\text {surf }}$ is the moisture content at the surface of the chicken meat sample $(\mathrm{kg} / \mathrm{kg})$ 
167 and $C_{\text {oven }}$ is the moisture content in the circulated ambient hot air. Table 1 summarizes the model input 168 parameters.

\section{3. Materials and Methods}

$170 \quad$ 3.1. Raw material and sample preparation

171 Chicken breast fillets without bones and skins were purchased at a local supermarket the same day as

172 the experiments. The chicken breast fillets were cut into a rectangular shape with a length, width and

173 height of 70, 40 and $20 \mathrm{~mm}$, respectively. The average weight of the sample was $63 \mathrm{~g} \pm 4$. The samples

174 were stored at $2{ }^{\circ} \mathrm{C}$ in sealed plastic bags until further usage.

\section{3.2. Roasting experiments}

176 The roasting trials were performed in a professional convection oven with dry hot air. The oven was

177 preheated for $30 \mathrm{~min}$ before the experiments to ensure steady state conditions. In this study, oven

178 temperatures of 200,230 and $260{ }^{\circ} \mathrm{C}$ were used. The temperature was regulated with the ovens

179 thermostat and it was found to be stable around the setting temperature with $\pm 3{ }^{\circ} \mathrm{C}$ (Rabeler and

180 Feyissa, 2018b). A single chicken meat sample was placed on the roasting tray which was then

181 positioned centrally in the oven. The roasting times in this study were $1,3,5,7,10,15$ and $20 \mathrm{~min}$.

182 After the specific roasting times, the samples were immediately taken out of the oven, put into plastic

183 bags and placed in ice water. Subsequently the color of the top surface and bottom surface of the

184 sample was measured (see section 3.3). 


\subsection{Color measurements}

186 For the color measurements a hyper spectral imaging system (VideometerLab 2, Videometer A/S,

187 Denmark) was used. The device was calibrated with a diffuse white and diffuse black (radiometrical calibration) target as well as with a geometrical target (geometrical calibration) (Hansen, 1999). The colors of the chicken breast samples were evaluated after 1, 3, 5, 7, 10, 15 and 20 min of roasting

190 (see section 3.2). First the color at the top and bottom surface of the roasted chicken meat sample was measured. One sample was placed underneath the camera and an image of the top surface was taken.

192 Afterwards the sample was turned over and another image of the bottom surface was taken. For the internal color measurements, the sample was cut in half (perpendicular to the length axis) and an image was taken from the internal cut surface.

195 The images were then processed with MATLAB (R2017a, The Mathworks Inc., MA, USA) and the average surface colors of the chicken meat samples were obtained as $L^{*}$ value (lightness), $a^{*}$ value

197 (green to red color) and $b^{*}$ value (yellow to blue color) (Rabeler and Feyissa, 2018a).

\subsection{Model solution and parameter estimation}

199 The commercial finite element (FEM) software COMSOL Multiphysics ${ }^{\circledR} 5.3$ was used to solve the 200 partial differential equations (PDEs) for the transport phenomena (see section 2.3) and the ordinary 201 differential equations (ODE) that describe the lightness changes of the chicken breast meat (see section 2.1 and 2.2). Mesh sensitivity analysis was conducted, to ensure the quality of the mesh. The mesh size was decreased in a sequence of simulations until the size had no effect on the solution of the model (Kumar and Dilber, 2006; Rabeler and Feyissa, 2018b).

205 The developed model was calibrated and validated by using experimental data for the change in the 206 surface lightness of the chicken meat sample at different oven temperatures (see section 3.2 and 3.3). 
207 The experimental data of the top surface color for an oven temperature of $230^{\circ} \mathrm{C}$ was used to estimate 208 the start temperature for browning, $T_{b}$ (Eq. (4b)), and the kinetic parameters in Eq. (3). COMSOL was 209 coupled with MATLAB (R2017a, The Mathworks Inc., MA, USA) by using the COMSOL 210 LiveLink ${ }^{\mathrm{TM}}$. The parameter estimation was done by minimizing the sum of the squared differences 211 between the experimental and the predicted lightness development at the top surface of the chicken 212 meat sample (non-linear least squares, Isqnonlin solver in MATLAB) (Feyissa et al., 2011).

213 The remaining measurements for the lightness developments at the top and bottom surface of the 214 chicken meat sample were then used to validate the developed model.

\section{3.5. Statistical analysis}

216 Analysis of variance (one-way ANOVA without replication) and Tukey's honestly significant

217 difference procedure was performed to assess the influence of the heating time and oven temperature 218 on the lightness changes of the chicken breast meat during roasting. The significance level for the 219 analysis was set to $\mathrm{P}<0.05$. The estimated parameters and measured values are presented as mean 220 values \pm confidence intervals at $95 \%$.

221 The standard root mean squared error (RMSE) was calculated with Eq. (10):

$222 \quad R M S E=\sqrt{\frac{\sum_{i=1}^{n}\left(\hat{\theta}_{i}-\theta_{i}\right)^{2}}{n}}$

223 with $\hat{\theta}$ the predicted value, $\theta$ the measured value $n$ is the total number of samples. The RMSE together 224 with the randomness and normality of the residuals was used to evaluate the quality of the model 225 predictions. 


\section{Results and discussion}

\section{4.1. Modelling the internal color changes}

228 By combining the kinetic model for the chicken meat whitening (Eq. (1)) with the model of heat and 229 mass transfer (section 2.3) it is possible to predict the internal lightness changes during the roasting 230 process as a function of the local temperature change. The influence of the oven temperature on the 231 internal lightness changes during roasting is shown in Fig. 1. A good agreement between the model 232 predictions (solid lines) and the measured (symbols) lightness changes for all tested temperatures was 233 found. The root mean squared errors (RMSEs) between predicted and experimental values are 0.825 , $234 \quad 0.773$ and 0.848 at 200,230 and $260{ }^{\circ} \mathrm{C}$, respectively.

235 The influence of the oven temperature on the internal lightness change was not significant $(\mathrm{P}>0.05)$.

236 An increase of the oven temperatures leads to a faster heat up of the sample surface (see Eq. (8)).

237 However, the internal heat transfer from the surface towards the core is slow compared to the external 238 heat transfer $(\mathrm{Bi}=1.1>0.1)$, which also results in a decreased internal temperature rise (Rabeler and 239 Feyissa, 2018b). Since the internal whitening of the chicken meat is a function of the temperature 240 development with time (see Eq. (1)), it is reasonable that the oven temperature has no significant 241 influence on the internal lightness changes.

242 Moreover, a visual comparison between the simulated and measured color change with roasting time 243 for an oven temperature of $230^{\circ} \mathrm{C}$ is shown in Fig. 2. First, the surface of the chicken meat which is in 244 contact with the surrounding hot air and roasting plate (only bottom) is getting white. This whitening is 245 caused by the heat induced denaturation of heme-proteins and the change in structural proteins (Hughes 246 et al., 2014; King and Whyte, 2006). The whitening is faster from the bottom of the sample compared 247 to the top surface. This is due to a higher heat transfer from the roasting plate to the meat that leads to a 
248 faster temperature increase at the bottom surface (Rabeler and Feyissa, 2018b). The heat is then

249 transferred inside the chicken meat by convection and conduction which results in the internal

250 whitening of the meat.

251 After around 7 minutes of roasting the internal of the chicken breast meat became white $\left(L_{\text {int }}{ }^{*}=85.9 \pm\right.$

252 1) nearly reaching the equilibrium $L^{*}$ value $\left(L_{\infty}{ }^{*}=87\right)$ (see also Figure 2). The absence of any pink

253 inside the chicken meat is still used in kitchens to assess the doneness of the meat (cook and a look

254 approach). Chicken meat should be heated to an internal temperature of at least $72{ }^{\circ} \mathrm{C}$ to ensure the

255 safety of the product for the consumer. However, after $7 \mathrm{~min}$ of roasting at an oven temperature of 230

$256{ }^{\circ} \mathrm{C}$, the core temperature of the chicken meat reaches only $59^{\circ} \mathrm{C}$ (Rabeler and Feyissa, 2018b). Thus,

257 the chicken meat is not safe for the consumer, yet, even though it is already completely white. This

258 shows the advantage of the developed model to ensure the safety of the roasted chicken meat for the

259 consumer independently of the operator or chef.

\section{4.2. Modelling the surface color development}

261 The visual inspection of the roasted chicken meat sample top surfaces shows that two stages of color

262 change can be distinguished (Fig. 3). In the beginning of the roasting process ( 0 to around $3 \mathrm{~min}$ ) the

263 surface becomes white mainly due to the thermal denaturation of heme proteins (hemoglobin and

264 myoglobin) and to some degree due to the denaturation of structural proteins (Guidi and Castigliego,

265 2010; Rabeler and Feyissa, 2018a). Afterwards, the surface of the chicken meat dries out due to the

266 evaporation of water, which leads to a first decrease of the lightness (see for example at $230{ }^{\circ} \mathrm{C}, 5 \mathrm{~min}$ )

267 (Nakamura et al., 2011). When the surface temperature is further rising a browning of the surface can

268 be seen (for example after $5 \mathrm{~min}$ at $260^{\circ} \mathrm{C}$, Fig. 3). This can be correlated to non-enzymatic browning

269 reactions (mainly Maillard and caramelization reactions) that take place when the surface temperature 
270 is increasing above 85 to $90^{\circ} \mathrm{C}$ (Kondjoyan et al., 2014; Martins et al., 2001). Finally, when the surface 271 temperature is rising above $150{ }^{\circ} \mathrm{C}$, carbonization reactions take place, which are resulting in a further 272 darkening and even burning of the sample (see for example after 20 min at $260{ }^{\circ} \mathrm{C}$, Fig. 3) (Nakamura 273 et al., 2011).

\section{4.2.1. Model calibration}

275 For the roasting of chicken breast meat at an oven temperature $\left(T_{\text {oven }}\right)$ of $230^{\circ} \mathrm{C}$, the two stages of color 276 change (whitening and browning) can be distinguished by following the development of the top surface 277 lightness $\left(L_{t o p}^{*}\right)$ with roasting time (symbols in Fig. 4). First, the lightness is increasing showing the 278 whitening of the meat surface, followed by a decrease of the $L_{\text {top }}^{*}$ value, which can be associated with 279 the darkening of the sample surface. A similar trend was also reported for the infrared heating (grilling) 280 of fish (Matsuda et al., 2013; Nakamura et al., 2011) or microwave cooking of beef meat (Kondjoyan et 281 al., 2014). We found that the roasting time has a significant influence $(\mathrm{P}<0.01)$ on the lightness of the 282 chicken meat surface.

283 The coupled model for the transport phenomena and lightness changes of chicken breast meat during 284 roasting was calibrated by fitting the experimental data $\left(L^{*} \exp , 230{ }^{\circ} C\right)$ to the corresponding model 285 predictions (see section 2.4). Consequently, the kinetic parameters in Eq. (3) ( $p_{0}, p_{1}, p_{2}$ and $p_{3}$ ) and the 286 start temperature for browning in Eq. (4b), $T_{b}$, were estimated.

287 The parameter estimation showed, that the lightness starts to decrease at surface temperatures around $288 T_{b}=88 \pm 2{ }^{\circ} \mathrm{C}$ (see Eq. (4b)), which corresponds to the start of the surface browning. The identified 289 temperature is in the same range as reported for beef meat $\left(85^{\circ} \mathrm{C}\right)$ or fish products $\left(95^{\circ} \mathrm{C}\right)($ Kondjoyan 290 et al., 2014 and Matsuda et al., 2013, respectively). The temperature $T_{b}$ distinguishes between the two 291 mechanisms of whitening (lightness decrease) and browning (lightness increase) (see section 2.2). As it 
292 was identified by the parameter estimation, a better insight into the mechanisms of the chicken meat 293 surface browning during heating is obtained. The kinetic parameters $p_{0}, p_{1}, p_{2}$ and $p_{3}$ in Eq. (3) were 294 estimated to be $6.369 \times 10^{6} \pm 1.309 \times 10^{5}, 1.2943 \times 10^{6} \pm 1.488 \times 10^{5}, 6.477 \times 10^{3} \pm 711.4$ and $929.68 \pm$ 29562.49 , respectively. The comparison between the predicted and experimental $L_{\text {top }}^{*}$ values shows that the 296 calibrated model is able to predict the development of the top surface lightness during the roasting at $297230^{\circ} \mathrm{C}$ (filled circles in Fig. 5). The root mean squared error (RMSE) between model predictions and 298 experimental values was estimated to be 1.31 .

299 The developed model was then validated against the measured lightness developments for oven 300 temperatures of 200 and $260{ }^{\circ} \mathrm{C}$ as well as the lightness developments at the bottom surface of the 301 chicken meat sample (see section 4.2.2).

\subsubsection{Validation of the developed model}

303 The validation of the developed model was done by comparing the predicted and measured lightness 304 development at the top and bottom surface of the chicken meat samples for oven temperatures of 200 305 and $260^{\circ} \mathrm{C}$. A good agreement between the predicted (solid lines) and measured (symbols) lightness changes at the top surface was found for all tested oven temperatures (Fig. 6a). The root mean squared error (RMSE) between the predicted and experimental values is 1.61 and 1.8 at 200 and $260{ }^{\circ} \mathrm{C}$, respectively. Additionally, the simulated lightness development at the bottom surface of the chicken meat samples agrees well with the measured values for all oven temperatures (Fig. 6b) with RMSE values of $2.29,1.09$ and 1.61 for 200,230 and $260{ }^{\circ} \mathrm{C}$, respectively. The comparison between the 311 predicted and experimental $L^{*}$ values for the top (filled symbols) and bottom (unfilled symbols) 312 surfaces is shown in Fig. 5. The results show that the developed model is able to accurately predict the 313 change in surface lightness during the roasting of chicken breast meat. 
314 We found that the oven temperature has a significant influence $(\mathrm{P}<0.05)$ on the lightness development 315 at the top surface of the chicken meat sample (Fig. 6a). An increase of the oven temperature from 200

316 to $260{ }^{\circ} \mathrm{C}$ results in a faster heat up of the sample surface (see Eq. (8)). Subsequently, the heme proteins 317 denature faster which leads to the faster whitening of the sample surface (Lawrie and Ledward, 2006;

318 Martens et al., 1982). Moreover, the transition temperature between whitening and browning $\left(88^{\circ} \mathrm{C} \pm\right.$ 3192 , see section 4.2.1) is reached earlier due to the more rapidly heat up. Consequently, an earlier 320 browning of the surface with increasing oven temperature was found. This earlier decrease of the $L_{\text {top }}^{*}$ 321 value also results in darker sample surfaces at all time steps (Fig. 6a).

322 The temperature at the bottom of the chicken meat sample (in contact with the roasting plate) is 323 increasing faster compared to the top surface due to a higher heat transfer coefficient (conduction) 324 which is also resulting in a higher moisture evaporation rate (Rabeler and Feyissa, 2018b). Thus, the 325 reaction rate constants for the whitening $\left(\left(k_{w}(T)\right)\right.$ and browning $\left(k_{b}\left(T, a_{w}\right)\right.$ period (Eq. 4$)$ are higher for 326 the bottom compared to the top surface. This is clearly illustrated in Figure 7.Accordingly, the lightness 327 at the bottom is changing faster compared to the top surface (Fig. $6 \mathrm{~b}$ and $6 \mathrm{a}$, respectively).

328 Overall, the results show that the developed model is able to accurately predict the change in the 329 lightness development at the top and bottom surface. The surface lightness is a function of the 330 temperature and moisture content development during roasting. Thus, by adjusting the oven settings it 331 is possible to directly impact the change of the surface lightness. The developed model can be used to 332 control the color change during the roasting process. Furthermore, the acquired knowledge in 333 combination with the developed model can be used to optimize the process of chicken meat roasting to 334 obtain a high quality product for the consumer. 


\section{Conclusion}

336 In this study, we have focused on the development of a mathematical model to predict the internal as 337 well as surface lightness $\left(L^{*}\right)$ development of chicken breast meat during convective roasting. First a 338 non-isothermal kinetic model was developed to describe the browning of the chicken breast meat 339 surface during roasting as function of the temperature and water activity changes. By combining the 340 kinetic model for browning with the before developed kinetic for the whitening of chicken breast meat 341 the temperature at which browning reactions at the chicken meat surface start was estimated. Thus, a

342 better insight into the mechanisms behind the browning of chicken meat during roasting was achieved.

343 Furthermore, the combination of the two kinetic models enables the prediction of both processes

344 (whitening and browning) with one equation.

345 The kinetic models were then coupled with the mechanistic model of chicken breast meat roasting 346 which allows the prediction of the internal as well as surface lightness development as function of the 347 local temperature and water activity changes. The validation of the developed model shows that both 348 the internal as well as surface lightness development can be predicted. Furthermore, the influence of 349 changing oven temperatures on the internal and external lightness development was obtained. We 350 found that the oven temperature has a significant influence on the top surface lightness development $351\left(L^{*}{ }_{t o p}\right)$. However, no significant influence of the oven temperature on the bottom $\left(L^{*}\right.$ bot $)$ and internal 352 lightness $\left(L^{*}{ }_{i n t}\right)$ changes was found.

353 Overall, the developed model is able to predict the lightness changes inside and on the surface of 354 chicken breast meat during convective roasting from the local temperature and water activity changes 355 for different process conditions. Thus, the model can be applied to control the lightness development of 356 the chicken breast meat during convective roasting and at the same time ensure the safety of the final 
357 product. Furthermore, the roasting process can be optimized to obtain the product with the highest 358 quality for the consumer.

359 Nomenclature

\begin{tabular}{|c|c|}
\hline$a_{w}$ & water activity \\
\hline$C$ & mass concentration $(\mathrm{kg} / \mathrm{kg})$ \\
\hline$C_{e q}$ & Water holding capacity $(\mathrm{kg} / \mathrm{kg})$ \\
\hline$c_{p}$ & specific heat capacity $(\mathrm{J} /(\mathrm{kg} \mathrm{K}))$ \\
\hline$D$ & diffusion coefficient $\left(\mathrm{m}^{2} / \mathrm{s}\right)$ \\
\hline$f$ & Heaviside function \\
\hline$G^{\prime}$ & Storage modulus $(\mathrm{Pa})$ \\
\hline$h$ & heat transfer coefficient $\left(\mathrm{W} /\left(\mathrm{m}^{2} \mathrm{~K}\right)\right)$ \\
\hline$k$ & reaction rate constant $(1 / \mathrm{min})$ \\
\hline$k_{c m}$ & thermal conductivity chicken meat $(\mathrm{W} /(\mathrm{m} \mathrm{K}))$ \\
\hline$L^{*}$ & lightness \\
\hline$p$ & swelling pressure $(\mathrm{Pa})$ \\
\hline$T$ & temperature $(\mathrm{K})$ \\
\hline$t$ & time $(\min )$ \\
\hline$u$ & velocity $(\mathrm{m} / \mathrm{s})$ \\
\hline RMSE & Root mean squared error \\
\hline \multicolumn{2}{|c|}{ Greek symbols } \\
\hline$\beta$ & mass transfer coefficient $(\mathrm{m} / \mathrm{s})$ \\
\hline$\rho$ & Density $\left(\mathrm{kg} / \mathrm{m}^{3}\right)$ \\
\hline$\mu$ & Viscosity (Pa s) \\
\hline \multicolumn{2}{|c|}{ Subscripts } \\
\hline $\mathrm{b}$ & browning \\
\hline bot & bottom \\
\hline $\mathrm{cm}$ & chicken meat \\
\hline
\end{tabular}




\begin{tabular}{|ll|}
\hline int & internal \\
surf & surface \\
w & water \\
wh & whitening \\
\hline
\end{tabular}


References

362 Ames, J.M., Apriyantono, A., Arnoldi, A., 1993. Low molecular weight coloured compounds formed in xylose-lysine model systems. Food Chem. 46, 121-127. doi:10.1016/0308-8146(93)90023-9

Barbanti, D., Pasquini, M., 2005. Influence of cooking conditions on cooking loss and tenderness of raw and marinated chicken breast meat. LWT - Food Sci. Technol. 38, 895-901. doi:10.1016/j.lwt.2004.08.017

Choi, Y., Okos, M.R., 1986. Effects of temperature and composition on the thermal properties of foods. Food Eng. Process Appl. 93-101.

Datta, A.K., 2006. Hydraulic Permeability of Food Tissues. Int. J. Food Prop. 9, 767-780. doi:10.1080/10942910600596167

Dolan, K.D., 2003. Estimation of Kinetic Parameters for Nonisothermal Food Processes. JFS Concise Rev. Hypotheses Food Sci. 68. doi:https://doi.org/10.1111/j.1365-2621.2003.tb08234.X

Eichner, K., Karel, M., 1972. Influence of water content and water activity on the sugar-amino browning reaction in model systems under various conditions. J. Agric. Food Chem. 20, $218-223$. doi:10.1021/jf60180a025

Feyissa, A.H., Gernaey, K. V., Ashokkumar, S., Adler-Nissen, J., 2011. Modelling of coupled heat and

Goñi, S.M., Salvadori, V.O., 2011. Kinetic modelling of colour changes during beef roasting. Procedia Food Sci. 1, 1039-1044. doi:10.1016/j.profoo.2011.09.155

Grunert, K.G., Bredahl, L., Brunsø, K., 2004. Consumer perception of meat quality and implications for product development in the meat sector - A review. Meat Sci. 66, 259-272. doi:10.1016/S0309-1740(03)00130-X 
384 Guerrero-Legarreta, I., Hui, Y.H., 2010. Handbook of Poultry Science and Technology, Volume 2: ed. $385 \quad$ John Wiley \& Sons, Inc. doi:10.1002/9780470504475

386 Guidi, A., Castigliego, L., 2010. Poultry Meat Color. Handb. Poult. Sci. Technol. Vol. 2 2, 359-388. 387 doi:10.1002/9780470504475.ch25

388 Haefner, J.W., 2005. Modeling Biological Systems: Principles and Applications. Springer-Verlag, New $389 \quad$ York. doi: $10.1007 / \mathrm{b} 106568$

390 Hansen, J.F., 1999. On chromatic and geometrical calibration. Technical University of Denmark. 391 Hughes, J.M., Oiseth, S.K., Purslow, P.P., Warner, R.D., 2014. A structural approach to understanding 392 the interactions between colour, water-holding capacity and tenderness. Meat Sci. 98, 520-532. 393

394 King, N.J., Whyte, R., 2006. Does it look cooked? A review of factors that influence cooked meat 395 doi:10.1016/j.meatsci.2014.05.022 color. J. Food Sci. 71, 31-40. doi:10.1111/j.1750-3841.2006.00029.x

Kondjoyan, A., Kohler, A., Realini, C.E., Portanguen, S., Kowalski, R., Clerjon, S., Gatellier, P., Chevolleau, S., Bonny, J.M., Debrauwer, L., 2014. Towards models for the prediction of beef meat quality during cooking. Meat Sci. 97, 323-331. doi:10.1016/j.meatsci.2013.07.032

Kumar, A., Dilber, I., 2006. Fluid Flow and Its Modeling Using Computational Fluid Dynamics, in: Sablani, S., Datta, A., Shafiur Rehman, M., Mujumdar, A. (Eds.), Handbook of Food and Bioprocess Modeling Techniques, Food Science and Technology. CRC Press. doi:10.1201/9781420015072

Lawrie, R.A., Ledward, D.A., 2006. Lawrie's meat science.

Ledl, F., Schleicher, E., 1990. New Aspects of the Maillard Reaction in Foods and in the Human Body. Angew. Chemie Int. Ed. English 29, 565-706. doi:10.1002/anie.197506551 
Related to Thermal-Denaturation of Muscle Proteins. J. Texture Stud. 13, 291-309.

Martins, S., Martins, S.I.F.S., Jongen, W.M.F., 2001. A review of Maillard reaction in food and implications to kinetic modelling A review of Maillard reaction in food and implications to kinetic modelling. Trends Food Sci. Technol. 11, 364-373. doi:10.1016/S0924-2244(01)00022-X

Matsuda, H., Llave, Y., Fukuoka, M., Sakai, N., 2013. Color changes in fish during grilling-Influences of heat transfer and heating medium on browning color. J. Food Eng. 116, 130-137. doi:10.1016/j.jfoodeng.2012.11.027

Nakamura, M., Mao, W., Fukuoka, M., Sakai, N., 2011. Analysis of the Color Change in Fish during the Grilling Process. Food Sci. Technol. Res. 17, 471-478. doi:10.3136/fstr.17.471

Namiki, M., Hayashi, T., 1981. Formation of novel free radical prodcut in early stage of maillard reaction. Prog. Food Nutr. Sci. 5, 81-91.

Ngadi, M., Dirani, K., Oluka, S., 2006. Mass Transfer Characteristics of Chicken Nuggets. Int. J. Food Eng. 2. doi:10.2202/1556-3758.1071

Pedreschi, F., León, J., Mery, D., Moyano, P., 2006. Development of a computer vision system to measure the color of potato chips. Food Res. Int. 39, 1092-1098. doi:10.1016/j.foodres.2006.03.009

Purlis, E., Salvadori, V.O., 2009. Modelling the browning of bread during baking. Food Res. Int. 42, 865-870. doi:10.1016/j.foodres.2009.03.007

Rabeler, F., Feyissa, A.H., 2018a. Kinetic Modeling of Texture and Color Changes During Thermal Treatment of Chicken Breast Meat. Food Bioprocess Technol. 1-10. doi:10.1007/s11947-0182123-4

Rabeler, F., Feyissa, A.H., 2018b. Modelling the transport phenomena and texture changes of chicken breast meat during the roasting in a convective oven. J. Food Eng. 237, 60-68. 
doi:10.1016/j.jfoodeng.2018.05.021

431 Shahidi, F., Samaranayaka, A.G.P., Pegg, R.B., 2014. Maillard Reaction and Browning, Encyclopedia of Meat Sciences. Elsevier Ltd. doi:10.1016/B978-0-12-384731-7.00130-6

Van Boekel, M.A.J.S., 2008. Kinetic Modeling of Food Quality: A Critical Review. Compr. Rev. Food Sci. Food Saf. 7, 144-158. doi:10.1111/j.1541-4337.2007.00036.x

Zanoni, B., Peri, C., Bruno, D., 1995. Modelling of browning kinetics of bread crust during baking. LWT - Food Sci. Technol. 28, 604-609. doi:10.1016/0023-6438(95)90008-X

Zhang, J., Datta, A.K., 2006. Mathematical modeling of bread baking process. J. Food Eng. 75, 78-89. doi:10.1016/j.jfoodeng.2005.03.058

439

440 
Table 1: Model input parameters (Rabeler and Feyissa, 2018b)

\begin{tabular}{|c|c|c|c|c|}
\hline Parameter & Symbol & Value & Unit & Source \\
\hline \multicolumn{5}{|l|}{ Density } \\
\hline chicken meat & $\rho_{c m}$ & 1050 & $\mathrm{~kg} / \mathrm{m}^{3}$ & $\begin{array}{l}\text { Calculated from (Choi and } \\
\text { Okos, 1986) }\end{array}$ \\
\hline water & $\rho_{w}$ & 998 & $\mathrm{~kg} / \mathrm{m}^{3}$ & \\
\hline Diffusion coefficient & $D$ & $3 \times 10^{-10}$ & $\mathrm{~m}^{2} / \mathrm{s}$ & (Ngadi et al., 2006) \\
\hline Permeability & $\kappa$ & $3 \times 10^{-17}$ & $\mathrm{~m}^{2}$ & (Datta, 2006) \\
\hline Viscosity water & $\mu_{w}$ & $0.988 \times 10^{-3}$ & $\mathrm{~Pa} \mathrm{~s}$ & (Rabeler and Feyissa, 2018b) \\
\hline \multicolumn{5}{|l|}{ Initial composition } \\
\hline Water & $y_{w 0}$ & 0.76 & $\mathrm{~kg} / \mathrm{kg}$ & (Rabeler and Feyissa, 2018b) \\
\hline Protein & $y_{p 0}$ & 0.22 & $\mathrm{~kg} / \mathrm{kg}$ & (Barbanti and Pasquini, 2005) \\
\hline Fat & $y_{f 0}$ & 0.01 & $\mathrm{~kg} / \mathrm{kg}$ & (Barbanti and Pasquini, 2005) \\
\hline Ash & $y_{a 0}$ & 0.01 & $\mathrm{~kg} / \mathrm{kg}$ & (Barbanti and Pasquini, 2005) \\
\hline Initial meat temperature & $T_{0}$ & 6 & ${ }^{\circ} \mathrm{C}$ & (Rabeler and Feyissa, 2018b) \\
\hline $\begin{array}{l}\text { Initial moisture } \\
\text { concentration }\end{array}$ & $C_{0}$ & 0.76 & $\mathrm{~kg} / \mathrm{kg}$ & (Rabeler and Feyissa, 2018b) \\
\hline $\begin{array}{l}\text { Water vapor concentration } \\
\text { in ambient air }\end{array}$ & $C_{\text {air }}$ & & $\mathrm{kg} / \mathrm{kg}$ & (Rabeler and Feyissa, 2018b) \\
\hline Heat transfer coefficient & $\begin{array}{l}h_{\text {top }} \\
h_{\text {bot }}\end{array}$ & & $\begin{array}{l}\mathrm{W} /\left(\mathrm{m}^{2} \mathrm{~K}\right) \\
\mathrm{W} /\left(\mathrm{m}^{2} \mathrm{~K}\right)\end{array}$ & (Rabeler and Feyissa, 2018b) \\
\hline
\end{tabular}




\section{Figure captions}

Figure 1: Comparison between the predicted (solid lines) and measured (symbols) lightness development inside the chicken meat sample during roasting at 200 (blue), 230 (black) and $260{ }^{\circ} \mathrm{C}$ (red). Bars indicate the standard deviation $(\mathrm{n}=3)$.

Figure 2: Visual comparison between the experimental (left side) and predicted (right side) color development inside the chicken meat sample during roasting at $230^{\circ} \mathrm{C}$.

Figure 3: Color development at the top surface of chicken breast samples roasted at 200, 230 and 260 ${ }^{\circ} \mathrm{C}$ for different roasting times $(1,3,5,7,10,15,20 \mathrm{~min})$.

Figure 4: Measured (symbols) and simulated (solid line) lightness development of the chicken meat top surface $\left(L_{t o p}^{*}\right)$ with roasting time for an oven temperature of $230{ }^{\circ} \mathrm{C}$. Bars indicate the standard deviation $(\mathrm{n}=3)$.

Figure 5: Comparison between the predicted and experimental lightness values. Filled and unfilled symbols show the top and bottom surface data points, respectively.

Figure 6: Measured (symbols) and predicted (solid lines) lightness development at the a) top and b) bottom surface of the chicken breast sample with roasting time. Bars indicate the standard deviation (n $=2)$.

Figure 7: Predicted development of the reaction rate constants $k_{w}$, Top Surface, $k_{w}$, Bottom Surface, $k_{b, \text { Top Surface }}$ and $k_{b \text {, Bottom Surface }}$ with roasting time $\left(T_{\text {oven }}=230^{\circ} \mathrm{C}\right)$. 


\section{Highlights}

- A non-isothermal kinetic model for the lightness changes of chicken meat was developed

- The surface browning is described as function of temperature, water activity and time

- The kinetic model was coupled with the mechanistic model of chicken meat roasting

- This allowed the prediction of the spatial lightness changes during convective roasting

- Model predictions and experimental measured lightness changes agree well 


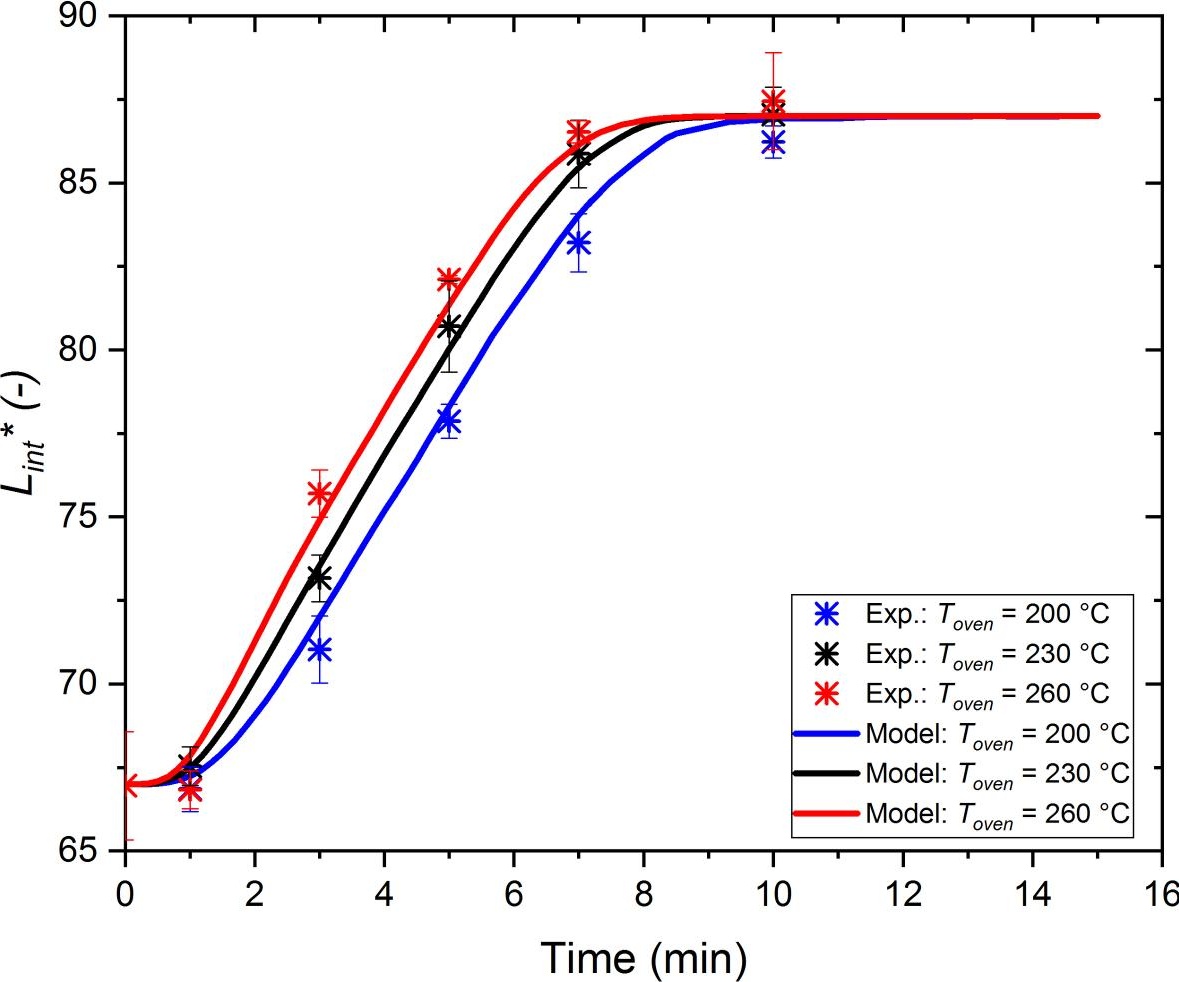


$1 \mathrm{~min}$

$3 \mathrm{~min}$
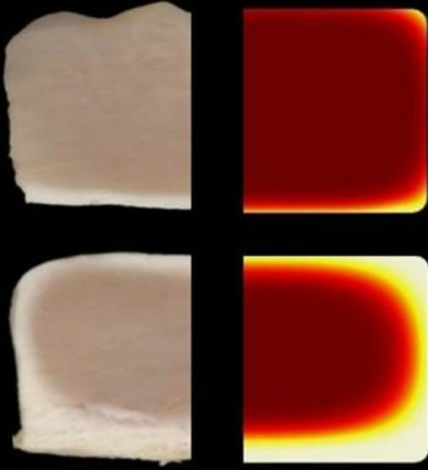

$5 \mathrm{~min}$
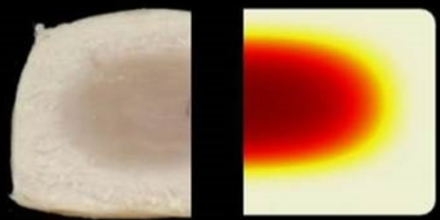

$7 \mathrm{~min}$
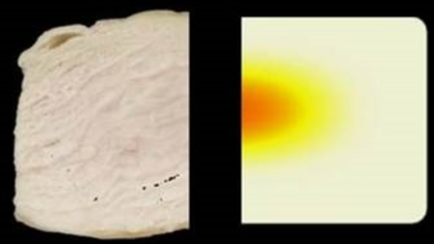

$10 \mathrm{~min}$
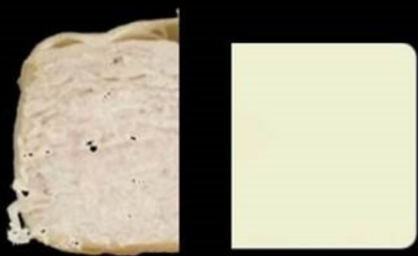


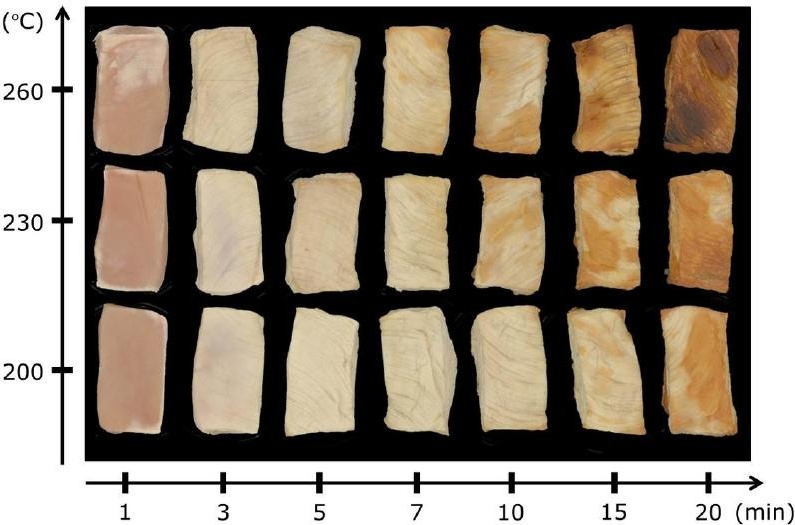




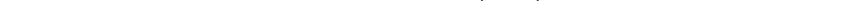




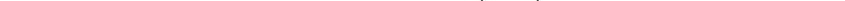




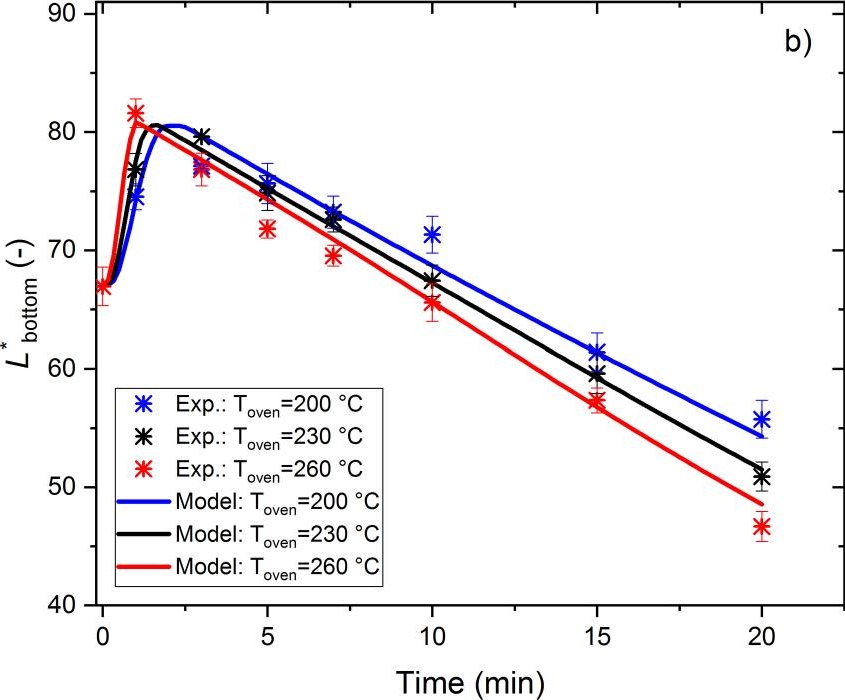




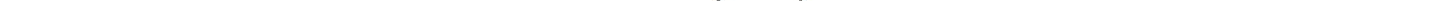

